\title{
A note on 'Modified proof of Caristi's fixed point theorem on partial metric spaces, Journal of Inequalities and Applications 2013, 2013:210'
}

Hassen Aydi ${ }^{1}$, Erdal Karapınar ${ }^{2}$ and Poom Kumam ${ }^{3 *}$

See related article: http://www.journalofinequalitiesandapplications.com/content/2013/1/210.

${ }^{*}$ Correspondence:

poom.kum@kmutt.ac.th

${ }^{3}$ Department of Mathematics,

Faculty of Science, King Mongkut's University of Technology Thonburi,

Bang Mod, Bangkok 10140, Thailand

Full list of author information is

available at the end of the article

\begin{abstract}
In this note, we emphasize that the proofs and statements of the main results of the paper 'Modified proof of Caristi's fixed point theorem on partial metric spaces' (Journal of Inequalities and Applications 2013, 2013:210) do not have any utility to use the partial metric. Hence, it has no contribution to either partial metric theory or Caristi-type fixed point problems.

MSC: $47 \mathrm{H} 10 ; 54 \mathrm{H} 25$
\end{abstract}

Keywords: Caristi's fixed point theorem; partial metric space; lower semi-continuous function

In the following, we use the same definitions, notations and structures given in [1]. We start first with Caristi's [2] fixed point theorem.

Theorem 1.1 [2] Let $(X, d)$ be a complete metric space. Let $f: X \rightarrow X$ and let $\phi$ be a lower semi-continuous function from $X$ into $[0, \infty)$. Assume that $d(x, f(x)) \leq \phi(x)-\phi(f(x))$ for all $x \in X$. Then $f$ has a fixed point in $X$.

Lemma 2.3 [3] Let $(X, p)$ be a partial metric space and let $p^{s}: X \times X \rightarrow[0, \infty)$ be defined by

$$
p^{s}(x, y)=2 p(x, y)-p(x, x)-p(y, y)
$$

for all $x, y \in X$. Then $\left(X, p^{s}\right)$ is a metric space.

To emphasize that the function given in (1) is a metric, we use the notation $d_{p}$ instead of $p^{s}$, that is,

$$
d_{p}(x, y)=p^{s}(x, y)=2 p(x, y)-p(x, x)-p(y, y) \quad \text { for all } x, y \in X .
$$

๑) 2013 Aydi et al.; licensee Springer. This is an Open Access article distributed under the terms of the Creative Commons Attribution License (http://creativecommons.org/licenses/by/2.0), which permits unrestricted use, distribution, and reproduction in any medium, provided the original work is properly cited. 
Let $(X, p)$ be a partial metric space. Following [1], consider $\phi: X \rightarrow[0, \infty)$ and $g: X \rightarrow X$ not necessarily a continuous function such that

$$
2 p(x, g(x))-p(x, x)-p(g(x), g(x)) \leq \phi(x)-\phi(g(x)), \quad x \in X .
$$

By (2), we can write

$$
d_{p}(x, g(x)) \leq \phi(x)-\phi(g(x)) .
$$

The author [1] defines the class of mappings $\Phi$ and $\Phi_{g}$ as follows:

$$
\Phi=\{f \mid f: X \rightarrow X \text { and } 2 p(x, f(x))-p(x, x)-p(f(x), f(x)) \leq \phi(x)-\phi(f(x))\}
$$

and

$$
\Phi_{g}=\{f \mid f \in \Phi \text { and } \phi(f) \leq \phi(g)\} .
$$

We re-write $\Phi$ as

$$
\Phi=\left\{f \mid f: X \rightarrow X \text { and } d_{p}(x, f(x)) \leq \phi(x)-\phi(f(x))\right\} .
$$

It is well known also that $(X, p)$ is complete if and only if $\left(X, d_{p}\right)$ is complete (see, e.g., [3, 4]).

Under these observations, keeping (2) in mind, we conclude that Lemma 3.1 in [1] remains true without using any properties of a partial metric. On the other hand, in Lemma 3.2 in [1] the completeness assumption is missed. It can be re-formulated correctly as follows.

Updated Lemma $3.2[1]$ Let $\left\{x_{n}\right\}$ be a sequence in a complete partial metric space $(X, p)$ such that

$$
d_{p}\left(x_{n+1}, x_{n}\right) \leq \phi\left(x_{n}\right)-\phi\left(x_{n+1}\right) \quad \text { for all } n \in \mathbb{N},
$$

where $\phi$ is a lower semi-continuous function. Then $\lim _{n \rightarrow \infty} x_{n}=\bar{x}$ and $d_{p}\left(\bar{x}, x_{n}\right) \leq \phi\left(x_{n}\right)-$ $\phi(\bar{x})$ for each $n$.

Moreover, in Definition 2.2 in [1], the open and closed balls associated to a partial metric $p$ are not defined correctly, because the term $p(x, x)$ is missing, that is, we should have

$$
B_{\varepsilon}(x)=\{y \in X, p(x, y)<p(x, x)+\varepsilon\} \quad \text { and } \quad \bar{B}_{\varepsilon}(x)=\{y \in X, p(x, y) \leq p(x, x)+\varepsilon\} .
$$

It is clear that there is nothing in this paper [1] to prove. Indeed, the main result of [1] is a consequence of Theorem 1.1.

The following definition already exists in the literature.

Definition $3.3(c f .[1])$ Let $(X, p)$ be a partial metric space. 
(1) For $A \subset X$, define the diameter of a subset $A$, written $D(A)$, by

$$
\begin{aligned}
D(A) & =\sup _{\left(x_{i}, x_{j}\right) \in A}\left\{2 p\left(x_{i}, x_{j}\right)-p\left(x_{i}, x_{i}\right)-p\left(x_{j}, x_{j}\right)\right\} \\
& =\sup _{\left(x_{i}, x_{j}\right) \in A} d_{p}\left(x_{i}, x_{j}\right) .
\end{aligned}
$$

(2) Let $r(A)=\inf _{x \in A}(\phi(x))$. Note that $B \subset A$ implies $r(B) \geq r(A)$.

(3) Let $\Phi^{\prime} \subset \Phi$. For each $x \in X$, define $S_{x}=\left\{f(x) \mid f \in \Phi^{\prime}\right\}$.

Keeping (2) in mind, we conclude easily.

Lemma 3.4 $[1] D\left(S_{x}\right) \leq 2\left(\phi(x)-r\left(S_{x}\right)\right)$.

Consequently, we derive Theorem 3.5 in [1] without using any property of the partial metric. As a conclusion, this paper is just a repetition of usual results by using equality (2).

\section{Competing interests}

The authors declare that they have no competing interests.

\section{Authors' contributions}

All authors contributed equally and significantly in writing this article. All authors read and approved the final manuscript.

\section{Author details}

'Department of Mathematics, Jubail College of Education, Dammam University, P.O. Box 12020, Jubail, 31961, Saoudi Arabia. ${ }^{2}$ Department of Mathematics, Atilim University, Incek, Ankara 06836, Turkey. ${ }^{3}$ Department of Mathematics, Faculty of Science, King Mongkut's University of Technology Thonburi, Bang Mod, Bangkok 10140, Thailand.

Received: 8 May 2013 Accepted: 12 July 2013 Published: 29 July 2013

\section{References}

1. Klin-eam, C: Modified proof of Caristi's fixed point theorem on partial metric spaces. J. Inequal. Appl. 2013, Article ID $210(2013)$

2. Caristi, J: Fixed point theorems for mappings satisfying inwardness conditions. Trans. Am. Math. Soc. 215, 241-251 (1976)

3. Matthews, SG: Partial metric topology. Research Report 212. Dept. of Computer Science. University of Warwick (1992)

4. Karapinar, E: Generalizations of Caristi Kirk's theorem on partial metric spaces. Fixed Point Theory Appl. 2011, Article ID 4 (2011)

\section{Submit your manuscript to a SpringerOpen ${ }^{\ominus}$ journal and benefit from:}

- Convenient online submission

Rigorous peer review

- Immediate publication on acceptance

- Open access: articles freely available online

- High visibility within the field

- Retaining the copyright to your article 